\title{
天草周邊に於ける重要生物の資源學的研究
}

\section{I. トビウヨに關する測定結果に就いて}

\author{
(昭和 23 年 11 月 13 日受理)
}

\section{村上于 郎一寡道重 明

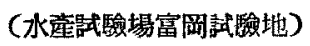

Studies on the Stocks of Some Economically Important Marine

Fishes caught around Amakusa

I. Results of Measurements of the Elying-fish,

Cypserulus agoo (Temminek\& Schlegel)

\section{S. MURAKAMI and 'S. SHINDO}

\section{SYNOPSIS}

The present is based on the measurements of the fying-fish, Cypserulus agoo (Temminck fi Schlegel), carried out at Tomioka from May to June in 1947. The fishing season of this species is nearly extending from the middle of May to the latter part of June at the said districts. It measures from $170 \mathrm{~mm}$ to $290 \mathrm{~mm}$ in body length, being thickly distributed between $180 \mathrm{~mm}$ and $210 \mathrm{~mm}$. But we can not separate some groups from the composition of body length. The body weight shows slso a similar composition to the former in bearing one mode, and we can not recognize some different groups from this.

The average numbers of vertebrae, dosal and caudal fin rays for each group are as follows; namely the first is $45.07 \pm 0.1337$ (S.E.) $\sim 45.69 \pm 0.1229$, the second. $12.90 \pm 0.1185 \sim 13.11 \pm 0.0743$ and the third $9.13 \pm 0.0735 \sim 9.33 \pm 0.1077$.

The fatness, $f\left(=\frac{W}{L^{3}} \times 1000: W\right.$, body weight in $\mathrm{g} ; L$, bodp length in $\mathrm{cm}$, shows a renge from 12.4 to 20.4 in male and from 13.7 to 19.7 in female. Its mean values of those individuals, which are contained within a range from $190 \mathrm{~mm}$ to 19.7 in female. Its mean values of those individuals, which are contained within a range from $180 \mathrm{~mm}$ to $210 \mathrm{~mm}$ in body length, are 16.2 in male and 16.9 in female, the letter being somewhat higher than the former. Then we calculated the values of $k$ and $n$ of each group, which are indicators in a formula, $W=k L_{n}^{n} W$, body weight in $\mathrm{g} ; L$, body length in $\mathrm{mm}$;, and got the following results; namely, in male, $k$ lies from $1.04 \times 10^{-4}$ to $6.47 \times 10^{-4}$, and $n$ varies from 2.297 to 2.643 , while in female, $k$ is within a range from $2.93 \times 10^{-11}$ to $1.15 \times 10^{-3}$ and $n$ is extending from 2.154 ao 5.500 . Further, we computed the value of $\log k$ for each ind vidual, making

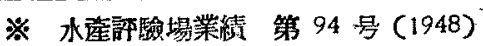


$n$ equal to 2.481 in male, an average value of total groups and 2.529 in female, a value obtaimed from total individuals, and made its frequency curve for each sex separately. As a result of this, it shows nearly a normal curve in male, while in female, it bears two peeks. Moreover, it is recognizable that $\log k$ somewhat incteases in value in "both male and female, as the season advances.

Measuring the weight of gonad, the testes are distributed almost normally, while the ovaries are divided into two groups which differ in the degree of maturity. Comparing the value of $\log k$ of the weight of gonad, the former becomes more or xess enlarged in both sexes, as the latter increases. Further, we computed the value of $\log k^{\prime}$, an indicater of body weight except the gonad, by a similar method to that of $\log k$, and compared it with the latter. In male, $\log k^{\prime}$ increases in value with the increment of $\log k$, while en female, the former decreases in value, when the latter becomes over $\overline{4} .300$.

Sex ratio of each group $\left(\begin{array}{c}\hat{b} \\ \phi\end{array}\right)$ varies from 0.27 to 0.66 , and is low in value at the middle of the season. The standard deviation of body length of each group $(\sigma)$ ranges from 0.60 to 1.20 , being higher in value at the beginning and the end of the season than at the middle of that. Moreover, $\sigma$ becomes larger in value, as the body increses in length.

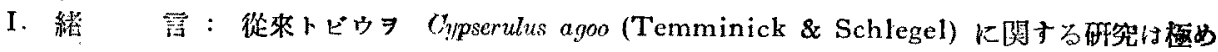

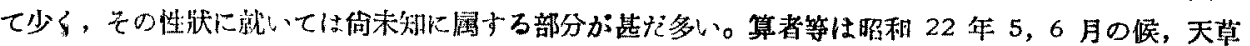

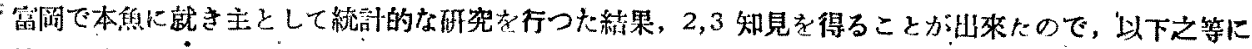

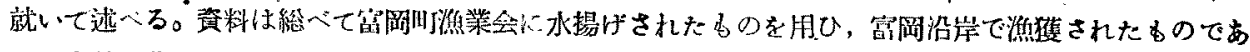

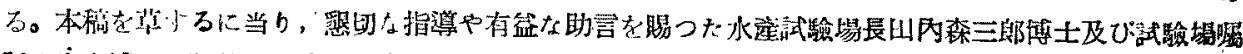

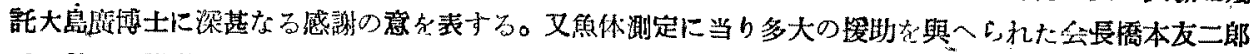
氏に昨せて謝意を表する。

II. 体長及び体重組成：天卓沿岸に於けろトビウ

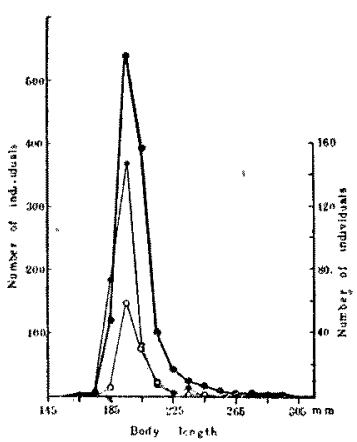

Fig. 1. Erequency curve of body length. Thick line, male and female mixed; 0 , male; $O$, female.

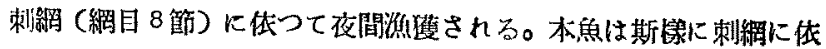

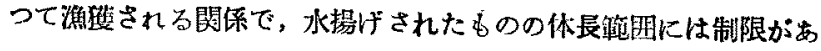
り，170mm 以下の個休怡んど見られなかつたが，大型黇にあつ

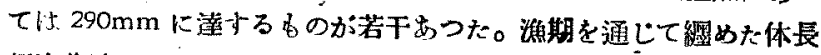
頻度曲線を是う子(

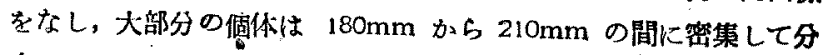

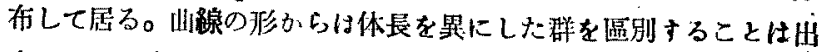

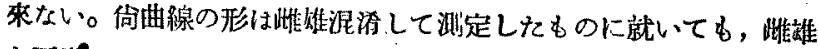

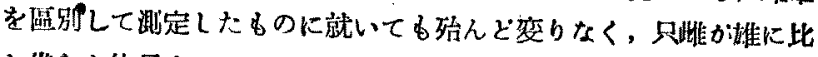
し幾らか体長大なるすに偏して居るのが諰められるに過ぎない。夯

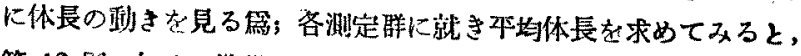

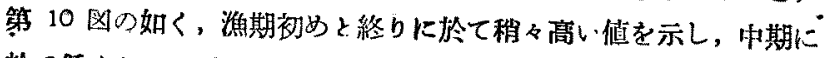

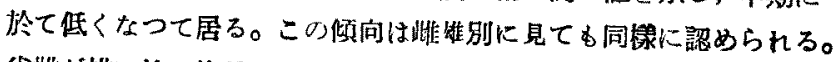

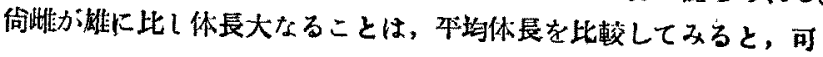


なりはつきり認められる。

次に体重頻度曲線を見ると，之双体長組成と同しく，モードをつ持つた曲線をなし，之からも体重

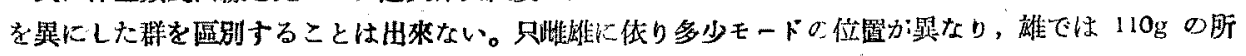

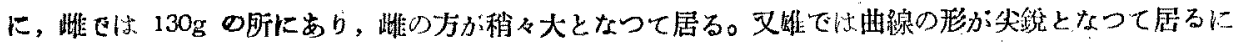

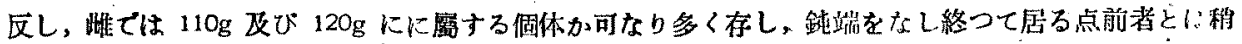
从趣を異にして居る。

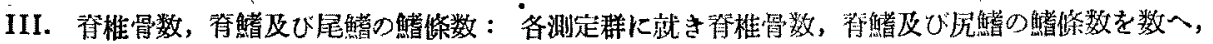

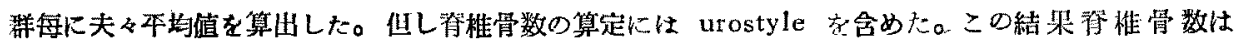

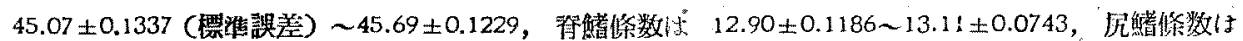

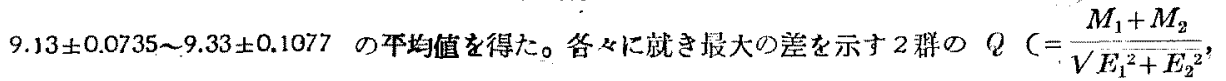

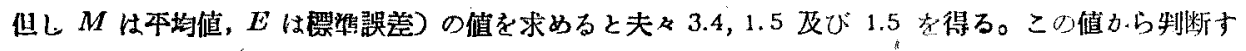

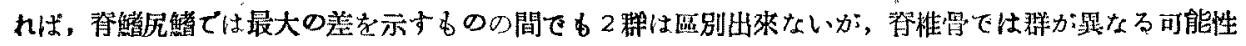
が考へられる。

IV. 肥 渵 度: 盵满度 $f\left(=\frac{W}{L^{2}} \times 1000\right.$, 但し $L$ は体長, $W$ は体重, 單位 $\left.\mathrm{cm}, \mathrm{g}\right)$ 妾部算し

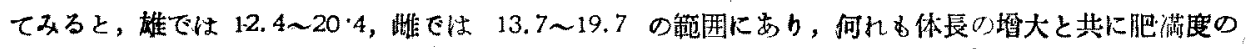

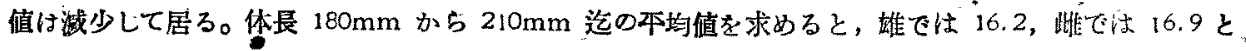
なり, 雌つ方か稍々高い値を示して居る。次に各湘定群に就き, 体長体重の関係式 $W=k L^{n}$ (但し單 位 $\mathrm{mm}, \mathrm{g}$ ) に於ける $k$ と $n$ の值を゙求めると, 雄では $k$ の值として $1.04 \$ 10^{-4} \sim 6.47 \times 10-4, n$ の倠

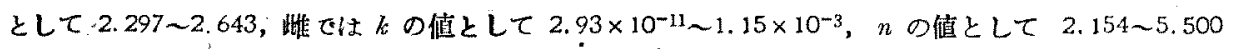

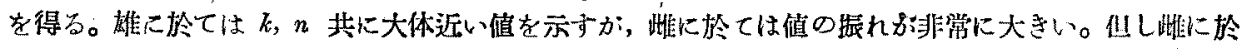

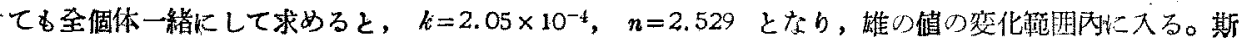

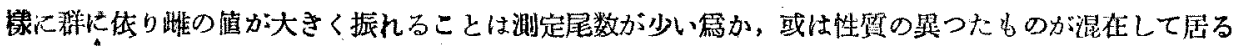
為か, 或は両者が重つた第であら5。今 $n$ を一定にして, 各個作に就き $\log k$ の值を求め, 雌婎别に

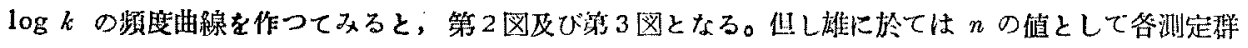

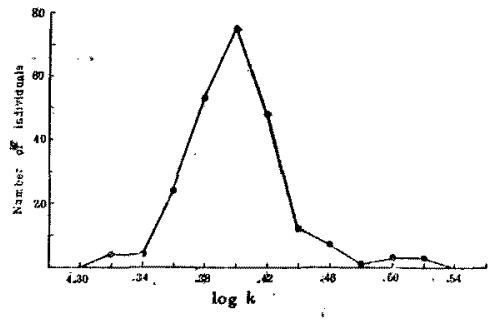

Fig. 2. Frequency curve of $\log k$ in male.

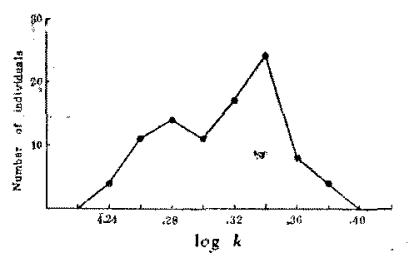

Fig. 3. Frequency curve of $\log k$ in female.

の $n$ の平均値 2.481 をとり，雌で全個体一緒にして求めた $n$ の值 2.529 をとつて計算した。图に

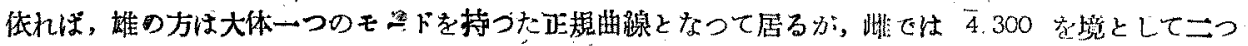
の群に分たれることが制る。

炏化各測定群に就き $\log k$ の平均值を求め, 特間的な变化を見ると, 非雄共漁期の経過と共に幾ら

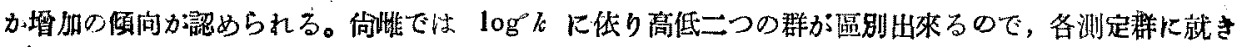




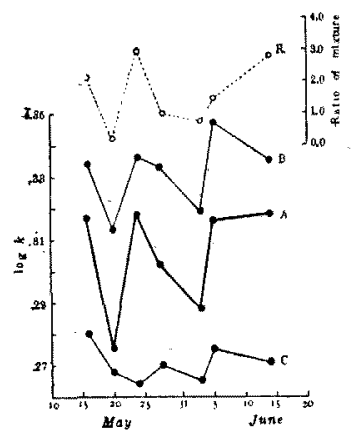

Fig. 4. Seasonal variation of $\log k$ in female. $A$, high and low value groups mixed; B, high value group; $\mathrm{C}$, low value group; $R$, ratio of number of endiviuals belonging to $B$ to that of $\mathrm{C}$.

低、群の個体数に対する湢い群の個休数の比索求め， $\log k$ の平均 值の動きと比較してみると可ならよく一致した变化を示して居る。

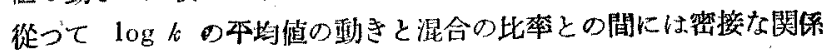
あることが推察される。所が各测定碓を高低2 稀に分つて夫ょ平均 値を田してみると，低い群の最初の1例を除げば,やはり两者共源

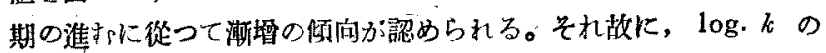
夫值自身も経過と共に次第に增大して居ると見るべきですらら第 4 図)。

V. 生殖巢重量: 生殖巢の重量を澌定した絬果, 雄では

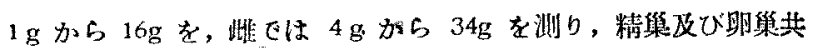

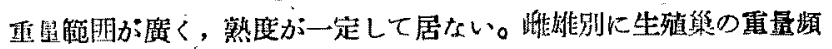
度州線を画いてみると，第 5 図及び第6 図の如く，雄では大体正規 ，暗線をなして分布して居るが，雌では略か $13 \mathrm{~g}$ 省境にして熟度を 異にした 2 稀が監別出来る。次に生殖集重量と $\log k$ との関係を

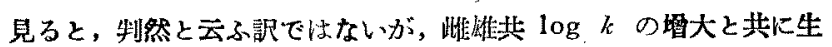

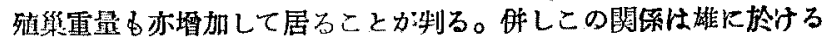

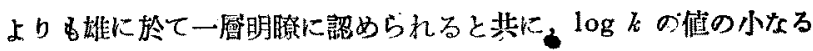
群が射䒩重量の小なる群に，前者の大なる群が後者の大なる群に夫

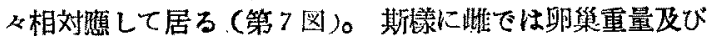

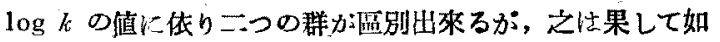
何なる理由に低るのか今く所不明である。又既に述てた如

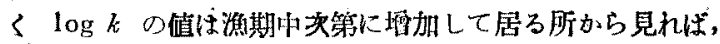

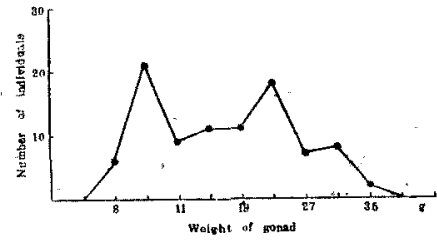

Fig. 5. Frequency curve of weight of testis.

Fig. 6. Frequency curve of weight of overy.

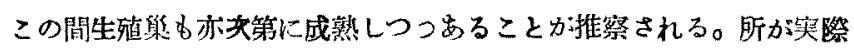

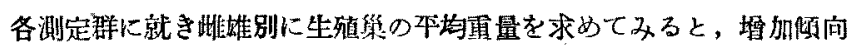

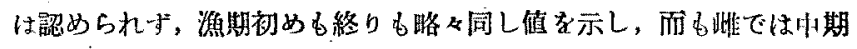

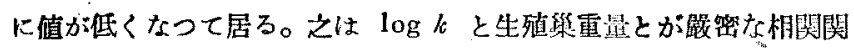

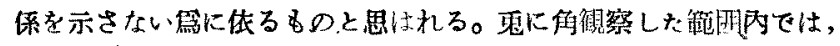

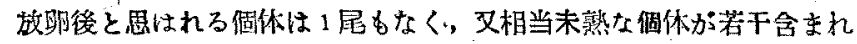

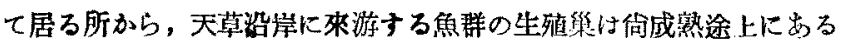
と見るべきであらう。

头に生殖条を除いた魚体の重量と $\log k$ との関俰を見よ弓。生殖 临を除いた魚体に就き $\log k$ の値を求めたと同じ方法で值を求め(婎

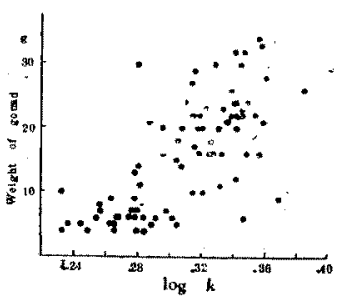

Fig. 7. Relation of weight of ovary to $\log k$. 


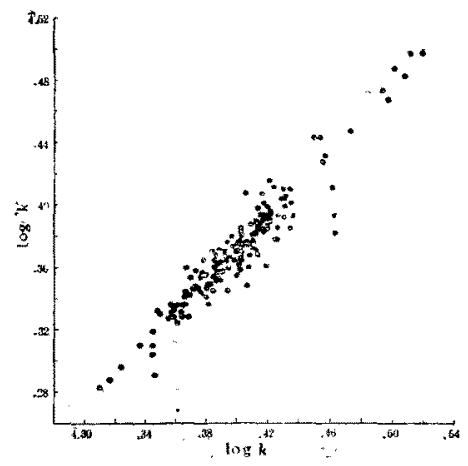

Fig. 8. Relation between $\log k$ to $\log k^{\prime}$ in male.

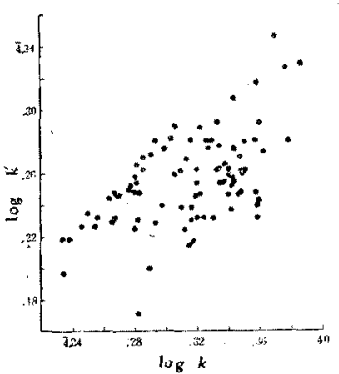

Fig. 9. Relation of $\log k$ to $\log \dot{k}^{\prime}$ in female.

では $n=2.481$, 非では $n=2.529$ として针算), 之を $\log k^{\prime}$ と して $\log k$ との関係を見ると第 8 园及び第9图となる。雄ては

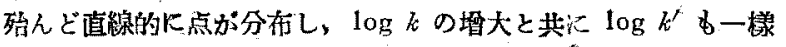
に罾大して居るに反し，此ては最初は䧸の場合之同じく $\log k$ の墰大と共に $\log k^{\prime}$ の增大が見られるか， $\log k$ の值が 4.300

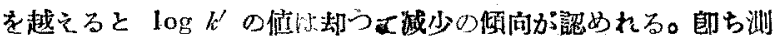

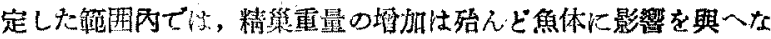

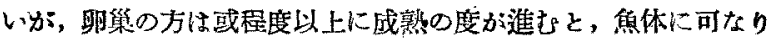

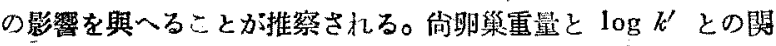
係を図示してみると， $\log k^{\prime}$ の減少を見るのは㖿集が 20 gを越 してからである。

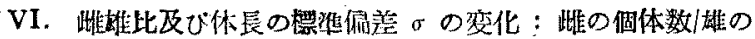

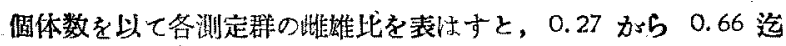

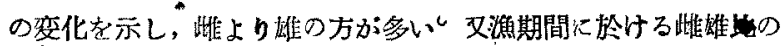

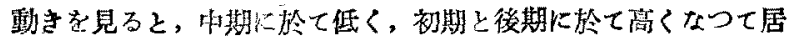

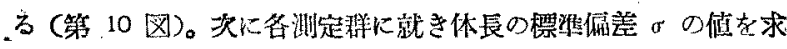
めると 0.60 加ら 1.20 の倠を示し，その钩きは之又前者と同㧼

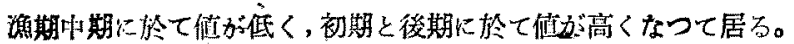

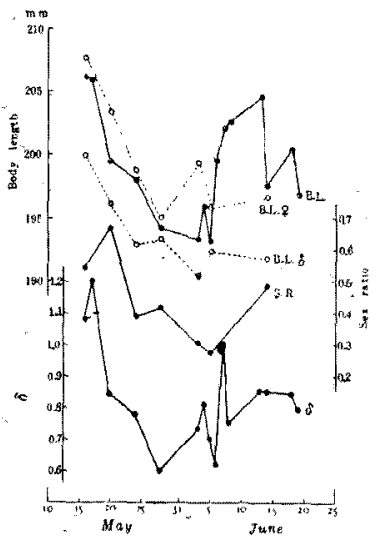

Fig. 10. Seasonal variations of sex ratio, body length and its standard deviation. B. L., mean body length; S.R., sex ratio; $\sigma$, standard deviation of body length.

(第 10 因)。文体長と $\sigma$ との関係を見ると，平均体長の小さい

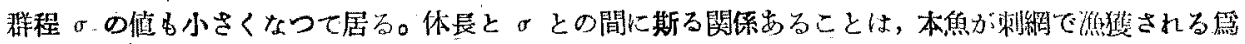

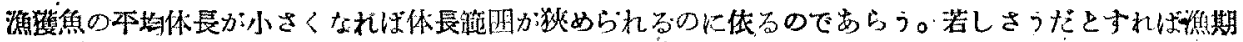

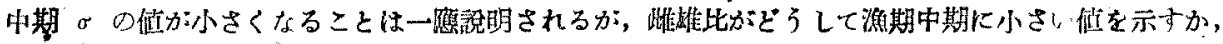
その理由方の所明かでい。 